\title{
IRONIA SOCRÁTICA: A ARTE DA DESTERRITORIALIZAÇÃO POR MEIO DE CANÇÕES
}

\author{
Jefferson Silva Queiroz ${ }^{1}$ \\ Vasco José Rocha Moreira Capêlo Nobre
}

QUEIROZ, J. S.; NOBRE, V. J. R. M. C. Ironia socrática: a arte da desterritorialização através de canções. EDUCERE - Revista da Educação, Umuarama, v. 20, n. 2, p. 483-502, 2020.

RESUMO: O presente trabalho apresenta uma proposta para utilizar a música em sala de aula com intenção de despertar os (as) alunos (as) para a leitura e consequentemente o espírito crítico sobre o mundo circundante. Durante a realização das atividades percebeu-se que, gradualmente a capacidade de questionar foi sendo despertada por meio da abertura e participação dos envolvidos naquela prática. Ao ler e falar sobre as letras das canções identificou-se que há mais do que melodia e ritmo em uma música, ela possui contexto, intenção, relação com o meio (político, social, econômico, familiar, religioso e etc.). Extrair das letras o prazer para além da satisfação rítmica e melódica foi uma experiência de amadurecimento e aperfeiçoamento de conceitos. Diante de todos os questionamentos gestados ao longo do processo da pesquisa, a problematização surgiu mediante a necessidade e a preocupação dos educadores: como tornar minha aula interessante e fazer com que meu aluno seja de fato protagonista do processo de ensino e aprendizagem?

PALAVRAS-CHAVE: Território; Rizoma; Ritornelo.

\footnotetext{
DOI: 10.25110/educere.v20i2.2020.7213

${ }^{1}$ Graduação em Filosofia pela Faculdade Padre João Bagozzi (2009). Graduação em Letras - Português/ Inglês pela Universidade Paranaense (2004). Especialização em Metodologia de Ensino de Filosofia e Sociologia (2013). Especialização em Língua Portuguesa e Literatura Brasileira (2007). Mestre em Arte e Educação pela Universidade Aberta Lisboa - UAB-PT (2015). E-mail: gel@prof.unipar.br ${ }^{2}$ Doctorat em Marketing Culturel (Arts\&Média) - Université Sorbonne Paris III (Grau reconhecido pela UAb, em 2007). Diplôme d'Etudes Supérieures Spécialisées, DESS, em Direction de Projets Culturels - Université Sorbonne Paris III. Pós Graduação em Tecnologias de Informação nas Empresas - Especialização em Desenvolvimento de Aplicações Multimédia - Universidade Católica - Lisboa. E-mail: vjrmcnobre@gmail.com
} 


\section{SOCRATIC IRONY: THE ART OF DETERRITORIALIZATION THROUGH SONGS}

ABSTRACT: The present work presents a proposal to use music in the classroom with the intention of awakening the students to reading and consequently their critical reasoning about the surrounding world. During the activities, it could be noticed that, gradually, the ability to question was being awakened through the openness and participation of the parties involved in such practice. When reading and speaking about the lyrics of the songs, it could be noted that there is more than melody and rhythm to a song, it has context, intention, relationship with the medium (political, social, economic, family, religious, etc.). Extracting from the lyrics the pleasure beyond rhythmic and melodic satisfaction was an experience of maturing and perfecting concepts. In face of all the questions generated throughout the research process, the problematization arose through the need and concern of educators: how to make my class interesting and turn my student into the key character in the teaching and learning process?

KEYWORDS: Territory; Rhizome; Ritornelo.

\section{IRONÍA SOCRÁTICA: EL ARTE DE LA DESTERRITORIALIZACIÓN A TRAVÉS DE CANCIONES}

RESUMEN: Esa investigación presenta una propuesta para utilizar música en clase, con intención de despertar los (las) alumnos (as) para la lectura y consecuentemente el espíritu crítico sobre el mundo circundante. Durante la realización de las actividades se percibió que, gradualmente la capacidad de contestar se ha despertado a través de la abertura y participación de los involucrados en aquella práctica. Al leer y hablar sobre las letras de las canciones se ha identificado que hay más que melodía y ritmo en una música, ella posee contexto, intención, relación con el medio (político, social, económico, familiar, religioso, etc.). Extraer de las letras el placer para además de la satisfacción rítmica y melódica fue una experiencia de maduración y perfeccionamiento de conceptos. Delante de todas las preguntas gestadas a lo largo del proceso de investigación, la problematización surgió mediante la necesidad y preocupación de los educadores: ¿cómo volver mi clase interesante 
y hacer con que mi alumno sea de hecho protagonista del proceso de enseñanza y aprendizaje?

PALABRAS CLAVE: Territorio; Rizoma; Ritornelo.

\section{INTRODUÇÃO}

Este trabalho trata de uma experiência realizada em uma turma do Terceiro ano do Ensino Médio, do Colégio Estadual Tiradentes, durante o ano de 2016, como proposta de um projeto de mestrado. O foco era trabalhar música a partir dos conceitos de devir e rizomas utilizados por Deleuze e Guattari.

O projeto sobre a utilização da música como instrumento de ensino-aprendizagem dentro da sala de aula surgiu a partir de sucessivas reuniões pedagógicas e conversas em momentos de hora atividade, onde professores das mais variadas disciplinas reclamavam da indisciplina em sala por parte dos alunos. As conversas tinham como pretensão descobrir uma maneira de conseguir chamar a atenção para os conteúdos. Mas, como fazer isso uma vez que os interesses dos alunos pareciam outros? Ao observarmos estes alunos, constatamos que atividades fora da sala em que eles eram protagonistas como júri simulado, apresentações artísticas das mais variadas possíveis (músicas, teatro, filmes, pinturas, quadros, etc.), viagens culturais, atraíam seus interesses tornando a aula mais agradável, além de despertar o interesse pelo conteúdo.

A questão que motivou a atual investigação foi: é possível que a partir de metodologias não convencionais os (as) alunos (as) se sintam mais motivado/as a ler, a discutir e a se apropriarem de fato dos conteúdos ensinados?

Segundo Castoldi e Polinarski (2009), grande parte dos (as) professores (as) receia utilizar metodologias alternativas à tradicional, onde acabam se valendo da exposição oral de um conteúdo e uma avaliação com questões objetivas e subjetivas visando ter um documento que comprove seu ensino e justifique a nota obtida pelo discente.

Após conversas com professores (as) de outras disciplinas que comungavam da mesma preocupação didático-pedagógica em suas aulas, ou seja, como tornar o ensino mais atraente aos discentes, surgiu como ideia, utilizar práticas metodológicas alternativas por meio de canções sem, contudo, comprometer os conteúdos estruturantes obrigatórios, 
presentes na LDB 9394/96. Vejamos o que nos fala a Lei de Diretrizes da Educação do Brasil. Citando o primeiro artigo e o segundo parágrafo do mesmo, podemos perceber qual a finalidade que a educação deve intentar em todas as suas dimensões:

Art. $1^{\circ}$. A educação abrange os processos formativos que se desenvolvem na vida familiar, na convivência humana, no trabalho, nas instituições de ensino e pesquisa, nos movimentos sociais e organizações da sociedade civil e nas manifestações culturais.

$\S 2^{\circ}$ A educação escolar deverá vincular-se ao mundo do trabalho e à prática social.

A integralidade da educação não pode ficar restrita única e exclusivamente à prática do ensino/aprendizado, mas a um conjunto de forças: Família, Estado, Escola e Docente em função de uma prática rizomática de educação onde viabilize vetores de desterritorialização e reterritorialização como nos exemplificam, os autores que serão os norteadores teóricos desta investigação, Deleuze e Guattari afirmam:

Qualquer ponto de um rizoma pode ser conectado a qualquer outro e deve sê-lo. E muito diferente da árvore ou da raiz que fixam um ponto, uma ordem. A árvore linguística à maneira de Chomsky começa ainda num ponto $\mathrm{S}$ e procede por dicotomia. Num rizoma, ao contrário, cada traço não remete necessariamente a um traço linguístico: cadeias semióticas de toda natureza são aí conectadas a modos de codificação muito diversos, cadeias biológicas, políticas, econômicas, etc., colocando em jogo não somente regimes de signos diferentes, mas também estatutos de estados de coisas (DELEUZE e GUATTARI, 1995a, p.15).

Ao lermos o segundo artigo proposto pela LDB, portanto, fica clara a importância inerente do papel da família e do Estado para o alcance da finalidade proposta. Deste modo, o Art. $2^{\circ}$. Fala que a educação, dever da família e do Estado, inspirada nos princípios de liberdade e nos ideais de solidariedade humana, tem por finalidade o pleno desenvolvimento do 
educando, seu preparo para o exercício da cidadania e sua qualificação para o trabalho.

Portanto, formar territórios é um ato natural resultante de atividades que conferem segurança à existência humana. O ser humano se constitui mediante uma teia de relações que são geridas a partir de um entrelaçamento de agenciamentos. $\mathrm{O}$ conhecimento resulta da interação do que se busca com os conteúdos buscados, mediado, porém pelas experiências e expectativas sempre abertas às possibilidades de existir e se tornar alguém no mundo.

Essas metodologias inovadoras estão conectadas com uma preocupação docente, com um ensino dinâmico, participativo e crítico, conforme citação:

Com a utilização de recursos didático-pedagógicos, pensa-se em preencher as lacunas que o ensino tradicional geralmente deixa, e com isso, além de expor o conteúdo de uma forma diferenciada, fazer dos alunos participantes do processo de aprendizagem. (CASTOLDI, POLINARSKI, 2009, p. 68).

Para melhorar o rendimento escolar (notas) e crítico (existencial) no e do mundo foi repensado o conceito de aprender rizomaticamente, de forma a promover o envolvimento e a realização de tarefas pedagógicas. Trabalhando em sala, uma dinâmica horizontal de aprendizado onde ninguém é detentor do saber, mas ele é construído por meio da participação dos (as) alunos (as), por isso as relações serão entendidas como um deviraluno (a) ou ainda um devir-músico (a), assim vejamos:

Devir é nunca imitar, nem fazer como, nem se conformar a um modelo, seja de justiça ou de verdade. Não há um termo do qual se parta, nem um ao qual se chegue ou ao qual se deva chegar. Tampouco dois termos intercambiantes. A pergunta 'o que você devém?' é particularmente estúpida. Pois à medida que alguém se transforma, aquilo em que ele se transforma muda tanto quanto ele próprio. Os devires não são fenômenos de imitação, nem de 
assimilação, mas de dupla captura, de evolução não paralela, de núpcias entre dois reinos. (DELEUZE, 2005, p. 24).

Cada pessoa traz consigo uma história de vida, um território ao qual se instalou ao redor da sua terra, seu porto seguro, sua moradia, sua forma de apresentação ao mundo. Quando entramos em contato com outras terras somos convidados a partilhar, a atravessar pelo território alheio ao nosso, mas que naquele momento e a partir dele seremos mutuamente afetados por sentimentos e experiências provindas das inúmeras vivências oriundas de cada um (a).

\section{Figura 1: A Arte da Dúvida}

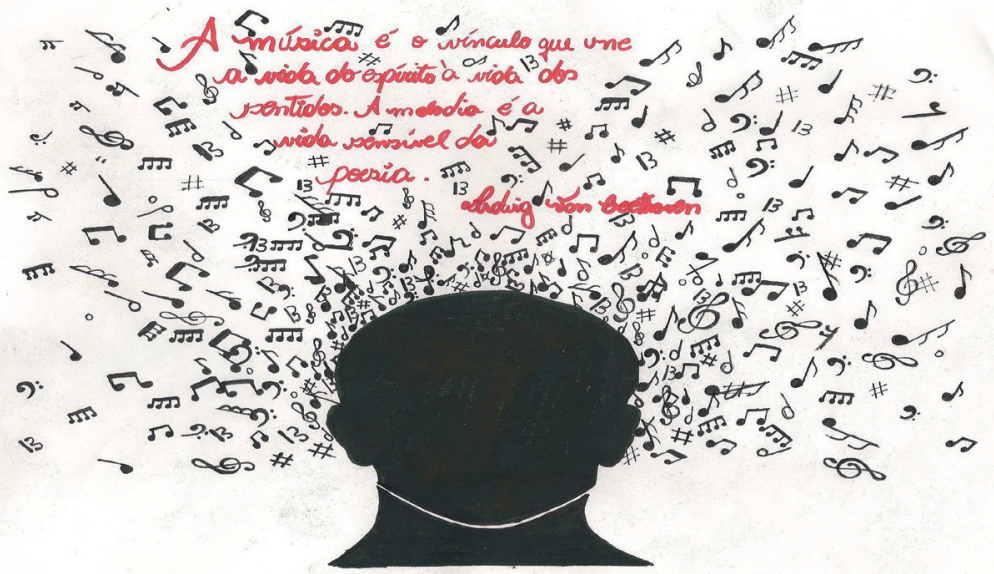

Fonte: Aluna Keren Aleixo Labs, 2015.

Ao longo do ano foram aplicadas inúmeras tarefas em sala para alcançarmos os objetivos propostos inicialmente. Durante este relato serão apresentadas algumas ações realizadas que corroboram para a constatação dos resultados do projeto em questão. 


\section{OBJETIVOS}

- Apresentar a música como um instrumento de ensino/ aprendizagem, onde por meio da leitura contextual seja possível entender a realidade circundante;

- Investigar a relação do conceito deleuziano de rizoma e a desterritorialização provocada pela música na produção humana de vida, tomando como referências músicas do cotidiano;

- Perceber que a música consiste num instrumento potencial de desterritorialização e reterritorialização, onde por meio do ritornelo encontraremos caminhos seguros para realizar intervenções no mundo.

- Desenvolver atividades pedagógicas de caráter interdisciplinar ligando-as às várias questões existenciais como subjetividade e singularidade, pobreza, relações de poder e saber, ética e autoestima.

\section{METODOLOGIA}

O estudo de caso consiste numa abordagem metodológica de caráter amplo, pois não se encerra a discussão, mas sempre abre novas possibilidades de reinterpretar o fato analisado, por outro lado concentra seus esforços no estudo de um caso bem definido sob o aspecto do interesse em encontrar uma solução para o problema proposto. Para Yin (1994, p.13), “[...] o estudo de caso é uma investigação empírica que investiga um fenômeno no seu ambiente natural, quando as fronteiras entre o fenômeno e o contexto não são bem definidas (...) em que múltiplas fontes de evidências são usadas".

A escolha por esta abordagem metodológica aconteceu em virtude de sua flexibilidade e adaptabilidade às mudanças durante o processo de estudo e aplicação. Uma vez que nem todas as tarefas desempenhadas aconteceram dentro do ambiente de sala de aula, é difícil precisar cientificamente os resultados, mas o estudo de caso permite que conforme houver necessidade, mediante o grau de variáveis percebidas, novos paradigmas serão aceitos como balizadores das experiências. O importante é que o caso seja sempre, compreendido, explorado e 
reavaliado de forma a promover os ajustes do foco motivador original do estudo.

Por isso, o estudo de caso é visto como a forma de organizar uma investigação, mais adequada, quando se procura responder de forma qualitativa pelas perguntas como e o porquê de acontecimentos, mais precisamente, que fazemos parte, como é o caso do professor dentro da sala de aula em relação com seus (as) alunos (as) e o ato de transmitir saberes curriculares, mas, sobretudo ultrapassá-los, despertando assim a consciência crítica de cada um (a) para serem agentes engajados social e politicamente.

Conscientes da importância que os educadores ocupam no desenvolvimento e na prática de técnicas orientadoras ao bom ensino e aprendizado dos (as) alunos (as), a problemática e o objeto do estudo de caso estão centrados nos seguintes pontos:

* práticas de leitura e interpretação das canções escolhidas;

* práticas deprodução artísticas nos alunos do terceiro ano A, que despertem neles o interesse pela participação, envolvimento e compreensão dos conteúdos curriculares;

* trocas de experiências pessoais sensibilizadas pelas canções;

As atividades foram realizadas entre os meses de fevereiro e novembro de 2016 e explicitam os instrumentos utilizados. A execução das atividades práticas do projeto seguiu o seguinte cronograma:

Tabela 1: Cronograma de atividades

\begin{tabular}{l|c|c|c|c|c|c|c|c|c}
\hline \multicolumn{1}{c|}{ ATIVIDADES } & $\mathrm{Fev}$ & Mar & Abr & Maio & Jun & Ago & Set & Out & Nov \\
\hline Reunião & $\mathrm{X}$ & & & & & & & & \\
\hline Pesquisa biográfica & & $\mathrm{X}$ & & & & & & & \\
\hline Leitura e partilha & & & $\mathrm{X}$ & & & & & & \\
\hline Apresentação das canções & & & & $\mathrm{X}$ & & & & & \\
\hline Criação musical & & & & & $\mathrm{X}$ & $\mathrm{X}$ & & & \\
\hline Analisando canções & & & & & & & $\mathrm{X}$ & & \\
\hline Cartografando as canções & & & & & & & & $\mathrm{X}$ & \\
\hline Avaliação & & & & & & & & & $\mathrm{X}$ \\
\hline
\end{tabular}

Fonte: Jefferson Silva Queiroz, 2015.

\section{DISCUSSÃO}

A canção "Pais e Filhos" (Renato Russo, Legião Urbana, As quatro estações, 1989). O que chamou a atenção dos (as) alunos (as) 
inicialmente foi o suicídio que ele comete e culpa seus pais por não o compreenderem, culpa os pais pelo tipo de vida que tem. A falta de amor próprio. Os conflitos familiares turbulentos. Começaram a pensar que, geralmente culpamos os pais ou outras pessoas pelas coisas que não deram certo em nossa vida, pelas decisões que tomamos sem consultar uma pessoa mais velha. Entenderam que responsabilidade é a capacidade de assumir o resultado das minhas escolhas, mesmo que elas não sejam o que eu esperava e que só assim serei livre para a felicidade.

Território - Suicídio.

Desterritório - Quem é o responsável ou culpado?

Reterritório - autoconsciência: o problema não é o que os outros falam de nós, mas o que fazemos com o que falam de nós.

A canção "Quando o sol bater na janela do seu quarto" (Renato Russo, Legião Urbana, As quatro estações, 1989). As primeiras intervenções questionaram a relação entre a claridade do sol e o início do dia, a preguiça de acordar cedo, a vontade de ficar mais um pouco na cama, sem seguida houve uma provocação do professor sobre a metáfora "o sol bater", O que significa bater? O que significa janela? O que significa dizer que "o caminho é o sol" e logo a imaginação começou a viajar por inúmeros significados possíveis e perceberam que as chances existem e que não podemos desperdiçá-las.

Território - o comportamento de uma geração.

Desterritório - o comodismo.

Reterritório - somos obrigados a nos posicionar; não importa o que fizeram com você, mas o que você faz com o que fizeram a você. 


\section{Figura 2: Atividade com Música}
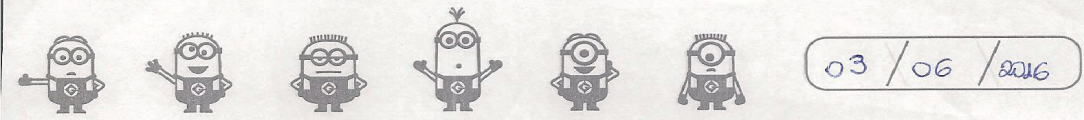

nome = Caroline

de Rlirrira

Claus $n \div 08$

3․ A

Gividiade sobre a música - Pais e Silhos

(1) Tema I Cssunto = trata -se da relacöo pai i filho.

2) mimouias = Isss une tray duas lembrangas: va primira i's fato de eu não compreender meus pais em veertos caspectos principaementa em me protiger, as nezes eu vão quero essa

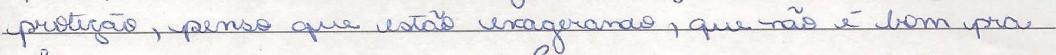
mim, mas unas rerdade a porque a que eles sentem por mim é 9 Cimor.

A sergunda l' da unimha relacão wom uminha vó, que a quase 2 anos faleceu, quama ula ura siva un uño dava a vatencäo que ela merecia, vriticava ou ate mermo nä exava Na os consulros vele, hoje que ela vä́ esta sinto falta, sinto que deveria ter excuta-la, mostrado \& que sinco por lek

(3) Intunçäo de cuttor = Ele terre imfluincia para fozer a música, com base una historia de uma unemina que tem problema iom Os yais a se jogou da fanela se matou.

I vautor e $\theta$ lara que interpretou a misica, acham ela for te porim lacana, porque retrata o cotidiaino de todos que é de pais para fillos

4) Intincão Pessoae = me faz ruffutir se estou dando realmente

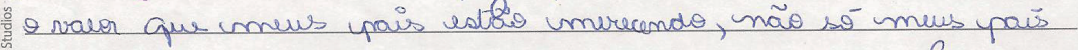
Las todes las uneu redor que ume tratam lem. Pensando : um como un seria como mäe, planejar yara que ele temera. um futuro bom, um vamor que nem meus yais estä ॠFonI me daras.

Fonte: Caroline de Oliveira, 2015. 
Figura 3: Atividade com Música

COLÉGIO ESTADUAL - TIRADENTES - ENSINO FUNDAMENTAL E MÉDIO.

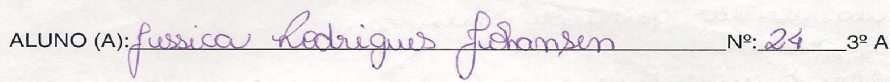

MARIA, MARIA

Maria, Maria

É um dom, uma certa magia

Uma força que nos alerta,

Uma mulher que merece viver e amar

Como outra qualquer do planeta.

Maria, Maria

Éo som, é a cor, éo suor,

Ea dose mais forte e lenta

De uma gente que ri quando deve chorar

$E$ não vive, apenas aguenta.

Masé preciso ter força,

E preciso ter raça,

É preciso ter gana sempre,

Quem traz no corpo a marca,

Maria, Maria

Mistura a dor e a alegria.

Masé preciso ter manha,

E preciso ter graça.

É preciso ter sonho sempre.

Quem traz na pele essa marca

Possui a estranha mania

De ter fé na vida.

ENTENDENDO O TEXTO

1. Identifique as características emocionais ou psicológicas da Maria descrita no texto.

2. A que classe social pertence a Maria descrita no texto? Transcreva o trecho que comprova sua resposta.

3. Quais trechos na música demonstram a necessidade de ter atitude perante as adversidades

4. Baseando-se no conteúdo do texto, explique o que afirmam esses versos: "Possui a estranha mania / de ter fé na vida".

5. A metáfora é uma figura de linguagem muito usada na linguagem poética. Identifique e transcreva as frases do texto que apresentam essa figura.

6) Que pessoas lutadoras e vencedoras a música te faz recordar.

1) Amar, whorar, aleguiou, Somhs i. fí., dor, Mi, porca

2) Uma pessoa trabalhadora, tabviz ula v' uma uscrava porque ino

unuésica dis que la unão vive, apenas aguenta, Ou una pussoa jeem tirra que luta para ter um Sugar para morrar. Maria, maria, \&́ is sum, l'a car, lé lo suor, 8 a dose imais porte u lenta. De wrna gente que vie

quande deve Shorar Bunão rrive, apenas afjeenta.

3) mas ú precise ter umamha,

8 - preciso ter graga,

8 prease ter sonto sempre.

Fonte: Jessica Rodrigues Johansen, 2015.

A canção "Por enquanto" (Legião Urbana, Legião Urbana, 1985). A preocupação dos discentes, inicialmente se concentrou em falar sobre o tempo de duração das coisas e das pessoas. Organizamos nossa vida em torno do tempo que levamos para conquistar e dominá-las. Alguns lembraram que muitos vivem na certeza de que nada irá mudar que tudo 
permanecerá como está ou como sempre foi. Nessa letra o professor chamou atenção da classe para o fator, contextualização. Entender a relação que há entre passado, presente e futuro. A vida é mais do que certezas ou pontos de vistas pessoais sobre os assuntos que eu tomo conhecimento.

Somos seres compostos de razão e sensibilidade, por isso somos capazes de atribuir sentido a tudo o que fazemos e, sobretudo ao que acontece conosco por forças extrínsecas que agem sobre nossa vida.

Território - o mundo das certezas, tudo é para sempre.

Desterritório - separação, ausência, afastamento.

Reterritório - o mundo é o local das mudanças.

A música possui em si uma potencialidade de desterritoriamento. Partir daquilo que me é próprio, comum, corriqueiro e que nem mesmo consigo definir ou delimitar consiste em entender o território de cada aluno (a) para promover direções. Precisamos saber com o que estamos lidando, de onde estamos saindo e para onde queremos ir ou chegar. Ao entrar em contato com outros mundos, outros horizontes, perspectivas ou leituras de mundo, acabamos por enfrentar nossos medos, enxergamos outros olhares, outros sentidos, outras respostas, vivemos um confronto contínuo, uma reelaboração de valores e posturas.

O confronto com o diferente por si só revela num primeiro momento um desconforto, num segundo momento, caso não estimula o prazer, o encanto, a sedução, acabam por causa a estranheza e consequentemente a rejeição. A desterritorialização neste caso é o confronto com o diferente, com a surpresa que conduziu cada um a pensar o que não haviam pensado as consequências de aceitação de uma escolha. A pergunta inevitável é: quanto eu sou responsável pelas minhas escolhas? O que devo fazer com as minhas escolhas após tê-las feito? As quais transformações minhas escolhas me conduzem?

Ao sair da nossa zona de conforto, ficamos durante um tempo impreciso perdidos em convicções até então seguras, mas que com o tempo serão confrontadas e testadas sob outros prismas. A reterritorialização se faz involuntária, mas ao mesmo tempo com uma nova consciência, capaz de provocar novos posicionamentos frente aos acontecimentos a que 
sou exposto durante toda minha existência. Retornar ao Território é um desafio, nunca conseguimos voltar ao mesmo lugar e nem do mesmo jeito que éramos. Reterritorializar é um processo de desenvolvimento, assim como o rizoma cresce para todos os lugares, em todas as direções, nossa existência vai adquirindo sentidos novos. Referindo-se ao rizoma, Deleuze e Guattari afirmam que "não é feito de unidades, mas de dimensões, ou antes, de direções movediças. Ele não tem começo nem fim, mas sempre um meio pelo qual ele cresce e transborda". (DELEUZE e GUATTARI, 2004, p. 32).

A principal característica do rizoma é sua capacidade de se multiplicar, de estar presente em vários locais ao mesmo tempo, fazendose entender sob qualquer olhar, sob qualquer direção. É possível a separação sem a perda de sentido, o processo rizomático viola a lógica do sentido aparente, ele funciona como um vírus que se propaga sem pretensões previamente acordadas ou determinadas, apenas se alcança outros territórios. Ao ouvirmos uma, duas, três ou mais vezes uma canção não há como mensurar o que sentiremos ou lembrar, ou ainda, quantas sinapses seriam possíveis realizar.

Um rizoma também é um mapa, ele nos orienta para caminhos nem sempre previsíveis:

[...] o mapa é aberto, é conectável em todas as suas dimensões, desmontável, reversível, suscetível de receber modificações constantemente. Ele pode ser rasgado, revertido, adaptar-se a montagens de qualquer natureza, ser preparado por um indivíduo, um grupo, uma formação social. (DELEUZE e GUATTARI, 1995, p. 22).

A escola é o ambiente onde adolescentes passam uma parte do seu tempo, são influenciados e influenciam os seus pares. É importante oferecer momentos onde a livre expressão e a criatividade sejam vistas como elementos formativos do ser aluno-pessoa. Diante desta constatação, aliar letras de músicas ao ensino se tornou um desafio primoroso, pois:

A função da música - tal como a da arte - repousa no sentido de proporcionar um tipo de autoexpressão livre. De fato, tem ela sido denominada "disciplina 
de expressão". Enriquece a vida da criança por meio das oportunidades que lhe oferece para participar dos sentimentos de outros e expressar seus sentimentos a outros, enquanto observa, ouve, executa e cria. Como disciplina socializadora, tem também grande valor. (BRÉSCIA, 2011, p. 86).

A criatividade foi exercitada ao longo de todo o ano letivo, por meio de atividades práticas como desenhos, apresentações de canções, charges, paródias e vídeos. Os (as) alunos (as) foram expostos a canções, biografias, comentários de profissionais, partilhas de visões e posicionamentos acerca das letras uns dos outros. As letras tinham temáticas variadas, acabavam falando sobre situações do cotidiano que eles (as) tinham contato com maior intensidade, seja em sua casa ou por ouvir de colegas. Fazer sempre as mesmas coisas torna o cérebro preguiçoso, por isso, pensou-se em um modo deles lerem, falarem e cantarem publicamente para que a vergonha, a falta de hábito, a falta de confiança ou ainda o famoso não sei fazer, fossem superados. Acreditando que as habilidades criativas que existem em todos nós quando crianças podem ficar adormecidas por um longo período de tempo e por inúmeras situações, foi que a proposta começou a ser desenvolvida.

As atividades significativas, segundo Faria e Dias (2007, p. 119), podem envolver experiências diversas e conhecimentos de diferentes áreas, já que a música contribui:

[...] para a construção de conhecimentos informais e formais sobre as linguagens, a natureza e a sociedade, atuando simultaneamente sobre o desenvolvimento da criança em todos seus aspectos: cognitivos, linguístico, social, afetivo, corporal, ético e estético. Além disso, contribuem de forma decisiva para sua formação como cidadã, incidindo na construção de sua identidade, de sua autonomia e de sua capacidade de participação e cooperação.

As primeiras canções foram vistas como novidade inicialmente, mas quando a proposta foi compreendida, os discentes perceberam que poderiam realizar as atividades com qualquer canção. Todas as canções 
possuem, contexto, letra, compositor, intenção e afetam de diferentes modos quem as ouve. O exercício, portanto tinha como meta ensinar a ser um crítico do que se ouve.

As atividades realizadas proporcionaram situações para experiências contínuas e interelacionadas com o aprendizado de vários campos do saber. Ao entender que todas as áreas estão relacionadas entre si e que aprendendo bem uma, estarei me capacitando para aprender as outras, tenho a música como uma potencializadora de habilidades. De acordo com Stefani (1987, p. 20).

a música afeta $[. .$.$] emoções, pois as pessoas vivem$ mergulhadas em um oceano de sons. Em qualquer lugar e qualquer hora respira-se a música, sem se dar conta disso. A música é ouvida porque faz com que as pessoas sintam algo diferente, se ela proporciona sentimentos, pode-se dizer que tais sentimentos de alegria, melancolia, violência, sensualidade, calma e assim por diante, são experiências da vida que constituem um fator importantíssimo na formação do caráter do indivíduo. 


\section{Figura 4: Avaliação, análise e triangulação dos dados coletados.}

\section{0) Qual música foi a mais significativa para você? Justifique sua resposta.}

1) Meu país, por que mostra como está o nosso país hoje em dia, faltando bastante coisa, pessoas, roubando pelas nossas costas, pegando nosso dinheiro e usando para outras coisas

2) Meu país, por abranger todos os aspectos tanto como política, social e psicológica. Levar a refletir um outro ponto de vista e o questionamento deste.

3) Eduardo e Mônica, pois retrata uma amizade que virou um grande amor, mesmo com todas as diferenças continuaram e formaram até uma família, e com essa música eu me identifiquei.

4) Pais e filhos, me identifiquei com a letra, pela questão da relação com meus pais, busquei mais entender eles e conversei a respeito de me entenderem. Foi uma lição de vida.

5) Pra ser sincero, pois descobri várias coisas ocultas na música, foi a música que mais me empenhei para entendê-la.

6) Para ser sincero chamou mais atenção.

7) Pais e filhos, pois a letra me ajudou muito a compreender a relação que eu tenho com o meu pai, me ajudou a entender e a perdoar tudo que aconteceu na minha vida e na vida dele.

8) Pais e filhos - Legião Urbana. Apesar de ser triste, me faz lembrar da minha história de família com meu pai. Mas a última serviu para ter mais conhecimento crítico então gostei também.

9) A música "Pra ser sincero", pois estimulou meu raciocínio e consegui ser produtiva.

10) Não respondeu

11) Meu País - Zezé di Camargo, pois tem as seguintes observações, política, social e econômica no desenvolvimento do nosso país.

12) Renato Russo -Índios, por que fala sobre os portugueses explorando os nativos brasileiros.

13) Meu País, por que ela fala da situação em que o país estava em 1998. Assim ela me fez refletir em como está a situação do nosso país hoje, que está igual na época de lançamento da música.

14) Monte Castelo, por que foi a música que eu e meu grupo cantou ou pelo menos tentou.

15) A música "Pra ser sincero" foi a mais significativa, isso por que foi a música que mais me empenhei a estudar por não se tratar de melhor música, todos os trabalhos em sala foram boas.

16) Meu País, pela letra da música ter sido criado à muito tempo atrás, retrata a realidade vivida atualmente.

17) A música Cidadão do Zé Ramalho, por que mostra a realidade de muitos trabalhadores que saem de suas terras natais em busca de condições melhores, porém acaba que não encontra o que queria.

18) Monte Castelo, foi a música que eu cantei esse ano com as meninas por mais que fiquei com vergonha foi bom perder um pouco de vergonha.

19) Música do Zezé di Camargo, por que fala do nosso País, das pessoas e o que falta para melhorar "Meu País".

20) Por enquanto foi uma das músicas que mais gostei em toda minha vida, foi muito significativa para mim, e aumentou ainda mais minha admiração pelo compositor da música integrante da Banda Legião Urbana, Renato Russo. Me fez, além do trabalho estabelecido pelo professor de realizar uma pesquisa sobre sua biografia, pesquisar um pouco mais a respeito deste grande cantor.

Fonte: Jefferson Silva Queiroz, 2015. 
Os relatos acima foram descritos por alguns (as) alunos (as) que quiseram expressar suas experiências com a música dentro da sala de aula, sendo utilizada como recurso e instrumento de ensino/aprendizagem.

Muito podemos aprender durante a vida, mas independente do que aprendemos é preciso reconhecer que há um número de caminhos a serem percorridos, e estes são infinitamente superiores ao que a nossa consciência é capaz de perceber e assimilar. Encantar-se pelo caminho, pelas novidades nele contidas, saber escolher dentre o que nos aparece, desenvolver um senso crítico frente à realidade que se abre a nós é um desafio, tanto árduo quanto valoroso, pois da capacidade de escolher bem resulta uma vida agradável. Aprender é uma atividade diária, mas o que fazemos com o que aprendemos é uma decisão singular e pontual, todos os dias somos cobrados pelo que aprendemos, por isso precisamos ser responsáveis com o ato de conhecer.

O conceito de rizoma e ritornelo ao serem utilizados pela primeira vez causaram estranhamento e desconforto nas aulas, mas aos poucos eles começaram a ser vivenciados, experimentados e até mesmo utilizados, timidamente, mas com referência ao conteúdo estudado. Por exemplo, quando estudamos a música "Pais e Filhos" do Renato Russo a aluna Caroline de Oliveira Claus comentou (ver quadro 3) "não compreender meus pais em certos aspectos, principalmente em me proteger, as vezes eu não quero esta proteção, penso que estão exagerando, que não é bom pra mim, mas na verdade é por que o que eles sentem por mim é o Amor". Neste comentário percebemos a ação de uma canção sobre a opinião aparentemente formada que estava pressuposta na fala. A música agiu como o meio desterritorializante de um modo de compreender a relação pais-filha, mas que quando refletida encontramos o sentido que ultrapassa as meras palavras. Constantemente somos formados pela relação que estabelecemos com quem está ao alcance do nosso convívio.

\section{CONSIDERAÇÕES FINAIS}

De acordo com o geógrafo Milton Santos ao tratar do "retorno do território", ou do território usado, como ele mesmo definia: O "território usado são os objetos e ações, sinônimo de espaço humano e espaço habitado" (SANTOS, 2002, p.16), onde se encontram as horizontalidades 
(lugares vizinhos, continuidade territorial, espaço banal) e as verticalidades (pontos distantes uns dos outros ligados por formas de processos sociais, redes).

A metodologia do rizoma confirmou que o conhecimento acontece de diferentes formas, velocidades e intensidades em cada indivíduo ao durante sua vida e de acordo com sua abertura, disponibilidade em realizar experiências. Alguns alunos (as) conseguiram perder a timidez para falar à frente da sala; outros (as) descobriram que para se relacionar com os familiares precisa-se de abertura ao diálogo e boa vontade de ambos os lados para que se harmonizem; aprenderam que a política organiza, planeja e interfere nos rumos da vida em sociedade, a cidade é o reflexo das decisões tomadas pelos representantes eleitos pelo povo, por isso é necessário que sejam representantes da vontade popular; entenderam que perguntar (a ironia socrática) é uma ferramenta poderosa contra o senso comum; compreender a origem e as fontes das informações contribui para formar um espírito crítico capaz de intervir quando preciso nas questões sociais que afetam o equilíbrio e o bem-estar entre os cidadãos. É inevitável pensar no poder que as mediações entre saberes criam sobre o desenvolvimento cognitivo e emocional dos indivíduos por um lado e como práticas metodológicas diferenciadas são bem-vindas entre os (as) estudantes para torná-los interessados nos conteúdos curriculares formais.

Estudar as canções utilizando o dispositivo do rizoma abriu um leque horizontal possível de leituras. Partindo de qualquer ponto traçamos linhas que formam territórios correlacionados, onde cada indivíduo passa a conviver com o território do outro, sendo afetado e afetando os significados que damos ao mundo e às nossas vivências. Construir pontes movediças que nos levem para qualquer lugar que seja importante ir, passa a ser uma tarefa processual e contínua na vida dos aspirantes ao conhecimento.

A grande lição para nós, professor e alunos (as) foi perceber que existe uma correlação equiparada de hierarquia, ou seja, mesmo o professor sendo a autoridade em sala de aula, o conhecimento não deve ou precisa estar sob o seu domínio, mas em relação de proporcionalidade entre as partes praticantes, e que o sucesso ou fracasso é apenas um ponto de vista que o sistema cobra para apresentação de dados científicos. Não podemos medir o aprendizado de alguém apenas pela nota obtida, 
embora seja esta a atual maneira de aprovar ou reprovar um (a) aluno (a), mas esta é uma maneira reducionista de enxergar o processo. Cada indivíduo possui um ritmo que segue um tempo dentro de uma velocidade e intensidade contínua, por isso é preciso respeito admiração a todos indistintamente. Diríamos aqui que a relação de Deleuze e Guattari com a música e o ensino/aprendizagem pode suscitar nos estudantes, aspirações ao engajamento social.

\section{REFERÊNCIAS}

ABBAGNANO, Nicola. Dicionário de Filosofia. 5. ed. São Paulo, Martins Fontes, 2007.

ADORNO, Theodor Wiesengrund. Indústria cultural e sociedade, trad. Julia Elisabeth Levy. São Paulo: Paz e Terra, 2002.

ARISTÓTELES. Política. Edição Bilíngue. (Trad. António Campelo Amaral e Carlos de Carvalho Gomes). Lisboa: Imprensa Nacional-Casa da Moeda, 1990.

BRÉSCIA, Vera Lúcia Pessagno. Educação Musical: bases psicológicas e ação preventiva. São Paulo: Átomo, 2003.

DELEUZE, Gilles; GUATTARI, Félix. O que é Filosofia? Tradução de Bento Prado Jr. e Alberto Alonso Muñoz. Rio de Janeiro: Imago, 1976.

DELEUZE, Gilles; GUATTARI, Félix. Mil Platôs: capitalismo e esquizofrenia, vol. 1, Trad. Aurélio Guerra Neto. Rio de Janeiro: Ed. 34, 1995.

DELEUZE, Gilles; GUATTARI, Félix. Mil Platôs: capitalismo e esquizofrenia, vol. 4, Trad. Suely Rolnik. São Paulo: Ed. 34, 1997.

FARIA, Vitória Líbia Barreto de; DIAS, Fátima Regina Teixeira de Salles. Currículo na educação infantil: diálogo com os demais elementos da Proposta Pedagógica. São Paulo: Scipione, 2007.

FARIA, Márcia Nunes A música, fator importante na aprendizagem. 
Assis chateaubriand - Pr, 40 f. Monografia (Especialização em Psicopedagogia) - Centro Técnico-Educacional Superior do Oeste Paranaense - CTESOP/CAEDRHS, 2001.

GUATTARI, Félix. Micropolíticas: cartografias do desejo. Trad. Suely Rolnik. Petrópolis, RJ: Vozes, 1996/2005.

GOHN, Maria da Glória; STAVRACAS, Isa. O papel da música na Educação Infantil. Eccos, São Paulo, v. 12, n. 2, p. 85-101. jul./dez. 2010.

HAESBAERT, Rogério. O Mito da Desterritorialização: do fim dos territórios a ultiterritorialidade. 5. ed. Rio de Janeiro: Bertrand Brasil, 2010.

PROUST, Marcel. Em Busca do Tempo Perdido. Obras Completas. Tradução: Mário Quintana. São Paulo: Editora Ediouro, 2002.

SARTRE, Jean-Paul. O existencialismo é um humanismo. Tradução: Vergílio Ferreira. São Paulo: abril S.A, 1973.

STEFANI, Gino. Para entender a música. Rio de Janeiro: Globo, 1987.

TRAVITZKI, Rodrigo. Rizoma é um sistema aberto (Deleuze e Guattari). Rizomas Educação e Cultura. 2008. Disponível em: http:// www.rizomas.net/filosofia/rizoma/107-rizoma-e-um-sistema-abertodeleuze-e-guattari.html. Acesso em: 08 jun. 2018.

Recebido em: 06/12/2018 Aprovado em: 10/07/2020 